\title{
Post-op bore profile estimation of workpiece clamped using three-jaw chuck
}

\section{Fatih GÜVEN}

Hacettepe University, Başkent OSB Vocational School of Technical Sciences, Department of Machinery and Metal Technology, Ankara, Turkey

\begin{abstract}
Estimating bore profile is important to select an appropriate tool for precision manufacturing in the process planning stage. Also, it helps in reducing the rejection rate of the process. A manufacturer might not be well-equipped and want to make their best with the resource on hand. Three-jaw chuck allows machining a wide range of workpiece, mostly circular parts in a lathe. However, clamping via a three-jaw chuck distorts the workpiece. In this study, the deformation of the bore profile was investigated numerically for circular parts. Finite element analyses were performed to examine dimensional variation for various materials and different wall thicknesses under fully elastic plane stress conditions. The stressed workpiece had a triangular form. Results showed that wall thickness and materials are important parameters on the triangulation of bore diameter. A simple calculation method based on thick-walled vessel theory was proposed to estimate the tolerance grade of the workpiece. This simple method provides the opportunity to reduce the rejection rate in the mass production of circular parts.
\end{abstract}

\section{Article info \\ History:}

Received:14.01.2020

Accepted:10.04.2020

Keywords:

Fit,

Cutting,

Machining,

Precision,

Tolerance.

\section{Introduction}

Machine elements need clearance between mating surfaces of parts in interaction. Form and dimensional tolerances are very important in shrink fits, bush, ball bearings, and plain bearings. In machinery, the workpiece has to be clamped because of the safety issue, however, clamping a workpiece causes its deformation nearby fixture and machining this localized stress zone could yield inaccuracy of dimensions [1]. This phenomenon could cause unbalanced stresses in machine elements such as a shrink fitted hub [2].

Circular parts are mostly clamped via three-jaw chuck for a drilling or a reaming operation. A certain clamping force is needed to fasten the workpiece during operation. During machining operation cutting force, $F_{c}$, produces a moment which is resisted by a frictional moment. This moment is a function of the friction coefficient between jaw and workpiece, $\mu_{g}$, and the clamping force, $F_{g}$, needed.

$$
F_{g}=\frac{F_{c} \cdot S_{k}}{\mu_{g}} \cdot \frac{d_{m}}{d_{g}}
$$

where $d_{m}$ is the machining diameter, $d_{g}$ is the clamping diameter, and $S_{k}$ is the safety factor. The cutting force is the multiplication of the specific cutting force $k_{c}$ and the cross-sectional area of the chip. The chipping section could be easily calculated using feed rate, $f$ and cutting depth, $a$.

$$
F_{c}=f \cdot a \cdot k_{c}
$$

This basic formulation is the basis of clamping, however, additional forces come out during machining operation such as centrifugal force, thermal forces, and frictional forces. Besides, clamping force losses are so important for both the accuracy of the process and its safety. Reducing clamping force may contribute to machining accuracy for a thin-walled workpiece in particular [3]. However, the insufficient clamping force could result in the loosening of the workpiece during operation due to centrifugal forces on jaws. It should be noted that clamping system failure could cause serious accidents in manufacturing. The clamping force also causes the deformation of the workpiece elastically or plastically. The bore diameter becomes smaller than its actual size under force and is to return its original diameter after discharging the 
clamping force. However, circular parts are no longer round when clamped via three-jaw chuck. Rahman [4] studied a tapered workpiece experimentally and concluded that the workpiece was a triangle from after machining. Brinksmeier et. al. [5] have shown that clamping an elastic ring via chuck leads to a variation of the cutting depth and polygonal form deviations could be observed. Kessler et. al. [6] have measured the out-of-roundness of a circular workpiece and stated that changes could extend up to $60 \mu \mathrm{m}$. The deformation depends on workpieces' and jaws stiffness as Malluck and Melkote [7] showed. The stiffness of these components also affects dynamic clamping force in high-speed turning [3]. Estrems et. al $[8,9]$ have investigated the deformation of rings made of aluminum both experimentally and numerically and proposed a mathematical model to calculate total deformation. In another study, Estrems et. al [10] have argued the effect of friction coefficient on clamping force and shape deviation. Bajpai [11] has proposed a diagram concerning the ratio of length to diameter to optimize workpiece size. Length is another parameter for the accuracy of workpiece tolerances. Maračeková et. al [12] have examined out-ofroundness of workpieces' open-end showed that clamping force may not affect the open end of the clamped workpiece according to the distance between open-end and chuck jaws. Similarly, Görög and Görögová [13] have examined out-of-roundness of the workpiece along the length of the part and showed the variation in roundness throughout the part length. In this case, it should be kept in mind that other form tolerances are needed due to the discrepancy between the two ends of the workpiece. Shawky et al. [14] have devised ultrasonic sensors to measure thickness variation of part during machining. Beekhuis et al. [15] proposed a method based on controlling the cutting depth of the clamped thin-walled part. Stöbener and Beekhuis [16] have applied an in-situ ultrasonic measuring system to compensates wall thickness variations during turning operations. These methods could reduce wall thickness variation of parts clamped inside, nevertheless, clamping parts outside could prevent accurate measurement of wall thickness due to jaws. Also, one can argue that using mandrel chucks could prevent the triangulation of the workpiece. Nevertheless, the operator needs a wide range of chucks due to the adherence of chuck to a specific dimension.

This study aims to provide a simple calculation method to estimate the degree of deformation due to clamping via tree-jaw chuck to reduce the rejection rate in mass production. In this study, the deformation of the bore profile was investigated numerically for various materials and different wall thicknesses under fully elastic plane stress conditions to reveal the relation between the triangulation of bore and the material and size of the part machined. A series of finite element analyses were performed to study the relation between dimensional variations and chuck press. A simple calculation method was proposed to estimate the tolerance grade of the workpiece. This simple method provides the opportunity to reduce the rejection rate in the mass production of circular parts.

\section{Material and Methods}

A series of finite element analyses were performed to investigate the bore profile of the workpiece clamped using a three-jaw chuck. The dimensions of the sample workpiece could be seen in Figure 1.

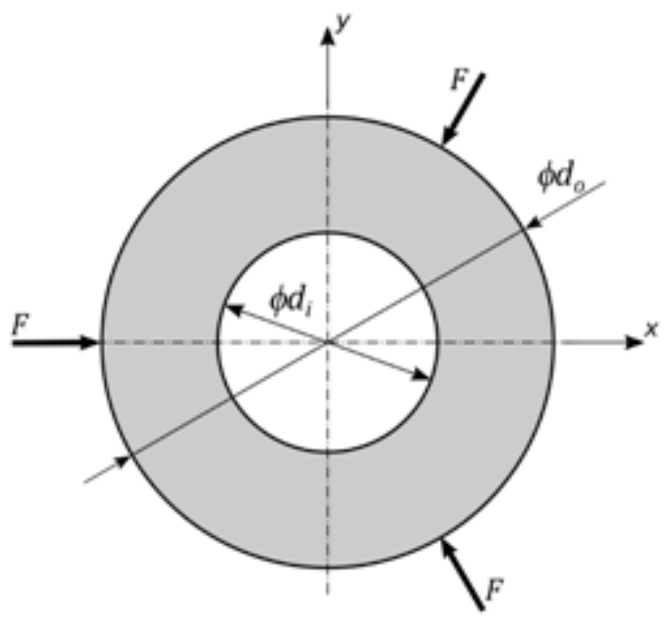

Figure 1. Dimension of workpiece

In the figure, the workpiece with an inner diameter of $d_{i}$ and an outer diameter of $d_{o}$ was subject to a force of $F$ on three equidistant points. Cyclic symmetry boundary conditions (frictionless support) were applied on low and high-end of the one-third model as shown in Figure 2. The low end and high end of the model are coincident with the $\mathrm{x}$-axis and the relative direction with an angle of $60^{\circ}$ from clamping force, respectively. The model was generated using twodimensional 8-noded quadrilateral elements with thickness options. It consisted of 2769 nodes and 880 elements smaller than $1 \mathrm{~mm}$. The degrees of freedom of the nodes on symmetry lines were equals to zero for the $\theta$ axis in cylindrical coordinate system. Considering the nature of jaw and part in contact, the clamping force applied as a distributed load of 260 $\mathrm{N} / \mathrm{mm}^{2}$ on an arc with a length of $4 \mathrm{~mm}$. The 
boundary conditions, applied loads and meshed the model are seen in Figure 2.

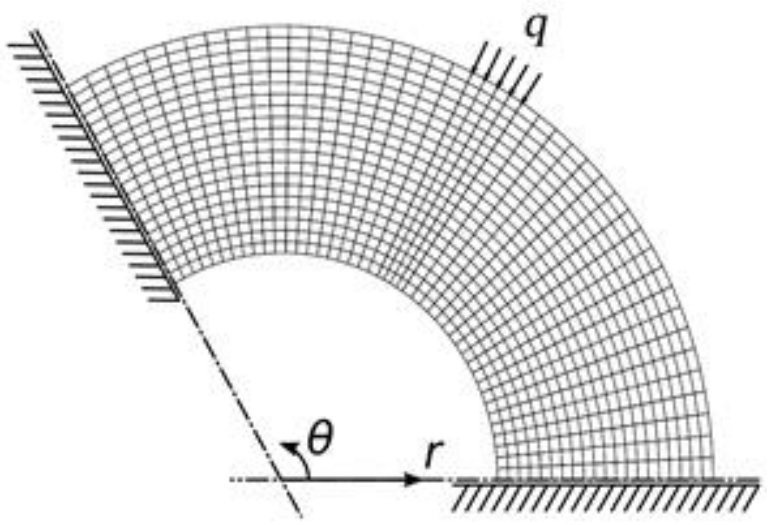

Figure 2. Cyclic sector model of workpiece.

Table 1. elastic properties of materials

\begin{tabular}{llll}
\hline Material & $\begin{array}{l}\text { Young's } \\
\text { Modulus, E (GPa) }\end{array}$ & $\begin{array}{l}\text { Poisson } \\
v\end{array}$ & ratio, \\
$\begin{array}{l}\text { Steel } \\
\text { (cold-rolled) }\end{array}$ & 203 & 0.287 & \\
$\begin{array}{l}\text { Bronze } \\
\text { (70-30) }\end{array}$ & 109 & 0.331 & \\
$\begin{array}{l}\text { Aluminum } \\
\text { (6061-T6) }\end{array}$ & 70.0 & 0.350 & \\
Magnesium & 44.8 & 0.350 & \\
\hline
\end{tabular}

The deformation of the bore profile was investigated for various materials and different wall thicknesses under fully elastic plane stress conditions. Elastic properties of materials used here are given in Table 1 [17]. The effect of material was examined on samples with a bore diameter of $20 \mathrm{~mm}$, an outer diameter of 40 $\mathrm{mm}$, and a thickness of $10 \mathrm{~mm}$. All other things being equal, only the outer diameter of the workpiece was altered to examine the wall thickness ratio in a range from 0.30 to 0.50 .

A negative change in dimension, i.e. the shrinkage of bore, yields an extra amount of chip and a positive change has a reverse situation. When the bore with a diameter of $D_{b}$ is machined, an amount of material, say $S$, will be removed, intentionally. After the operation, bore extends to a finishing diameter of $D_{f}$ as given in Eq. (3). However, the clamping force causes shrinkage of the workpiece and the cutting tool removes an additional chip with a thickness of $\Delta s$. When the clamping force is loosened, the dimension of bore extends up to $D_{f}+\Delta d$ as seen in Eq. (4). It would not be wrong to assume that pre-op shrinkage of bore equals to post-op relaxation of it under fully elastic strain assumption (Eq. (5).

$$
\begin{gathered}
D_{b}+S=D_{f} \\
\left(D_{b}-\Delta s\right)+S=D_{f}+\Delta d \\
-\Delta s=\Delta d
\end{gathered}
$$

All results are based on this assumption and dimensional variations are gathered in the cylindrical coordinate system. It should be noted that the shrinkage would not be equal throughout the bore diameter since the chuck subjects force on a limited area.

\subsection{Verification of model}

The aim of the study is figuring out a simple coefficient to estimate the bore profile by modifying known equations. We know the equations governing the fullypressurized thick-walled vessels. From this point of view, a partially pressurized cylindrical could be calculated by using a modified version of the equation used for fully-pressurized one.

The model has been verified using the formula for a pressurized thick-walled cylinder subjected to constant external pressure. The deformation of a cylindrical vessel is computed using well-known Lame's Equation. There is no radial stress at the inside of this kind of vessels when pressed at outside and tangential stress, $\sigma_{\theta}$, governs the deformation [18].

$$
\sigma_{\theta}=-2 p \frac{d_{o}^{2}}{d_{o}^{2}-d_{i}^{2}}
$$

We define the ratio inner diameter to outer diameter denoted as $q$ and rearrange the Equation (6):

$$
\sigma_{\theta}=\frac{-2 p}{1-q^{2}} ; \quad q=\frac{d_{i}}{d_{o}}
$$

From Hooke's law, dimensional variation, $\Delta d$, could be found easily. Substituting into the equation above yields:

$$
\Delta d=d \cdot \varepsilon=\frac{d}{E}\left(\sigma_{r}-v \sigma_{\theta}\right)
$$

In this study, constant pressure of $p=260 \mathrm{~N} / \mathrm{mm}^{2}$ was applied to the whole outside diameter of the model to verify the analysis. The finite element analysis showed good agreement with the calculation (Figure 
3 ). The internal tangential stress, $\sigma_{\theta}$, was equal to $693.21 \mathrm{~N} / \mathrm{mm}^{2}$ where the calculated was 693.33 $\mathrm{N} / \mathrm{mm}^{2}$ (relative error $0.017 \%$ ) for the elastic parameters of steel.

\section{Results and Discussion}

The jaws apply the pressure on contacting the surface of the workpiece and this yields

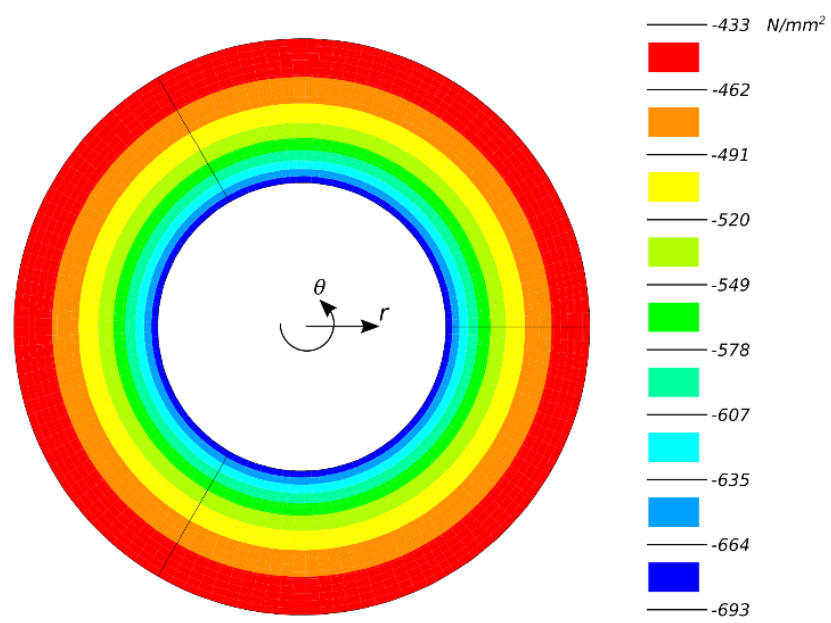

Figure 3. Tangential stress distribution of model under fully-presurized condition.

the clamping force $F$ which holds the workpiece to prevent any convenience during machining operation and stresses the workpiece clutched. The distribution of tangential stresses of the gripped workpiece is shown in Figure 4. The workpiece deforms under this stresses intrinsically. It can be clearly seen that the bore diameter of the workpiece remains elastic under a clamping force of $q=260 \mathrm{~N} / \mathrm{mm}^{2}$ on the contact area $(A)$ for the materials investigated in this paper. So, the equations are valid for the results presented in this section.

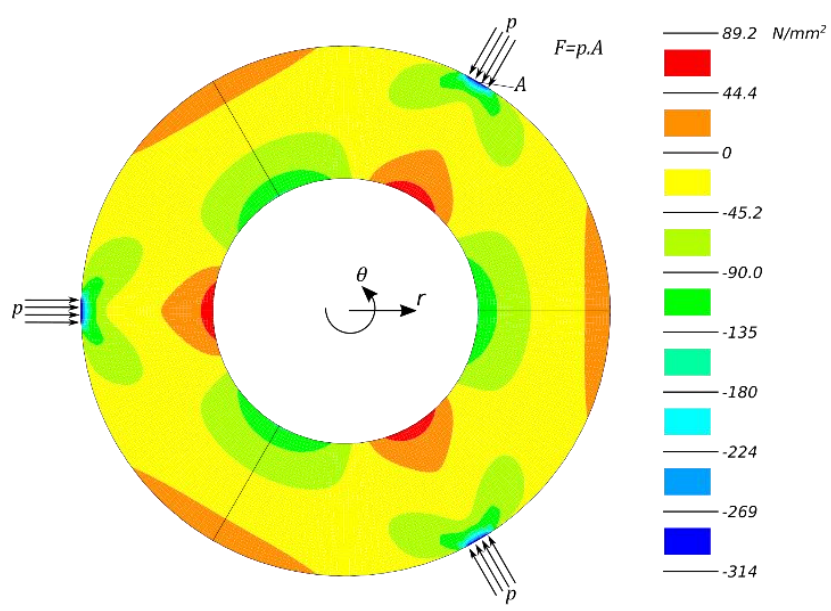

Figure 4. Tangetntial stress distribution of model under partially-resurized condition.
An exaggerated bore diameter profile of the workpiece made of steel is shown in Figure 5. As shown in the figure, the bore diameter of the clutched workpiece seems triangle. The operation with a circular tool removes an amount of substance that the sum of given chip thickness and displaced material as mentioned earlier. After loosening the workpiece, the bore diameter of the workpiece will expand due to relaxation. For steel material, the biggest size of the bore is $12.7 \mu \mathrm{m}$ greater than the smallest one under given conditions. The overstraining of the workpiece for clamping would affect die tolerance of bore. It stands out in the figure that the size of the bore gets its maximum value in the direction of the clamping force applied. Similarly, its minimum value is in a direction coincident with the symmetry line that has a relative angle of $60^{\circ}$ to the clamping force direction.

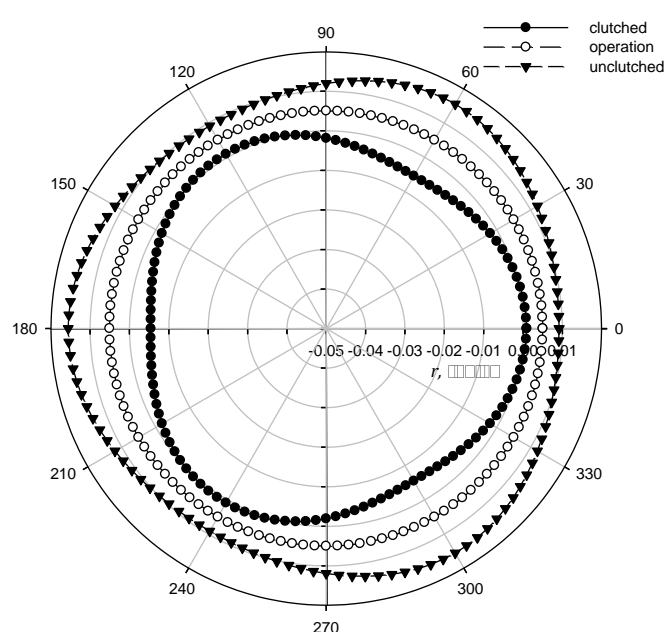

Figure 5. Deformation of bore diameter of steel workpiece before and after clamping.

The degree of deformation depends on the elastic properties of workpiece material. Figure 6 shows postop bore profiles of unclamped workpieces for different kinds of materials. It could be clearly seen that material plays an important role in the profile of bore. The triangulation of bore is considerably affected by Young's modulus of material. The biggest dimension of the bore is $12.7 \mu \mathrm{m}, 24.6 \mu \mathrm{m}, 38.2 \mu \mathrm{m}$ and $59.8 \mu \mathrm{m}$ for steel, bronze, aluminum, and magnesium, respectively. On the contrary, the clamping force direction, the bore size of the clamped workpiece is slightly greater than the free diameter of the bore. This variation and the triangulation of circle become prominent along with a decrease in Young's modulus. It could be concluded that the workpiece made of magnesium, the substance with the smallest Young's modulus among material investigated here, could not be functional under mid- and high-tolerance class. 


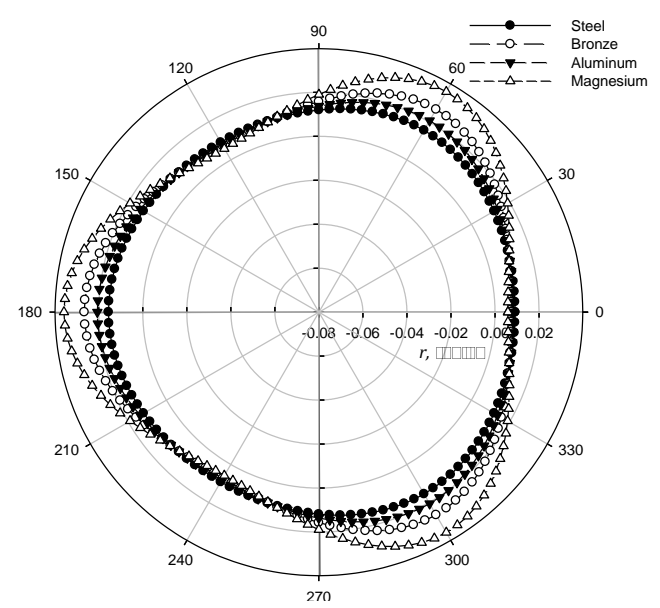

Figure 6. Profile of bore diameter for different materials.

Another parameter investigated here is the ratio of wall thickness to bore diameter $\left(s / d_{i}\right)$. As known, pressure vessels categorized into thin-walled and thick-walled regarding the ratio of wall thickness to bore diameter. This categorization specifies the formulae used for stress calculations in pressure vessels. As a sample, Figure 7 shows the post-op profiles of the unclamped workpiece made of aluminum. Similar to the pressure vessel, the ratio of wall thickness to bore diameter, the ratio affects the degradation level of the bore. As shown in the figure, the biggest size of the bore is 38.2 $\mu m, 43.4 \mu m, 50.6 \mu m, 61.1 \mu m$ and $77.5 \mu m$ for the $s / d_{i}$ ratio of $0.30,0.35,0.40,0.45$ and 0.50 , respectively. This means that the thinner the wall, the more the degradation under pressure. Also, the biggest dimension occurs in the clamping force direction inherently. As mentioned before, the dimension of bore gets bigger when the workpiece clamped. So, the realized bore dimension in the direction coincident with the symmetry line would be smaller than the expected value.

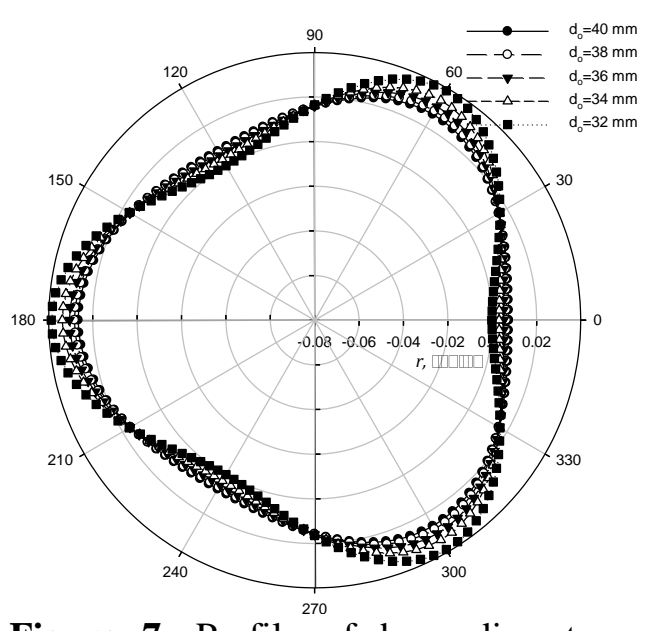

Figure 7. Profile of bore diameter of aluminum workpiece for different Wall thickness.

In machinery, form and dimensional tolerances are specified for a workpiece to be fitted. The degradation level should be within the specified tolerance limit. The dimensional deviations of investigated samples and their corresponding tolerance grade [19] with its value in brackets are seen in Table 2. While circular form tolerance would not pose a problem for steel, a fit part made of aluminum or a material with a similar Young's modulus should be studied carefully. Dimensional tolerances could be challenging in the manufacturing process of fit parts. As known, the lower the grade of tolerance, the more precise the part. A manufactured part that out of tolerance limit could not be functional upon design purpose and ends up as rejected part. Dimensions of parts examined in this paper vary in a wide range. This deviation is not desired for shrink-fitted joint in particular. The reason is that this joint transmits torque from a shaft to a hub, or vice versa, based on frictional force owing to contact pressure between mating surfaces. The clearance of fit designates the contact pressure and consequently the torque to be transmitted. Excessive contact pressure

Table 2. Categorization of post-op dimensions into tolerance classes

\begin{tabular}{lcccccc}
\hline Sample & \multicolumn{2}{c}{ Dimensional deviations $(\mu m)$} & \multicolumn{2}{c}{ Tolerance grade $(\mu m)$} \\
\hline Material & $s / d_{i}$ & SLD & FD & $\Delta d$ & Form* & Dimension \\
\hline Steel & & -1.78 & 11.0 & 12.7 & R (10) & IT7 (22) \\
Bronze & 0.50 & -3.42 & 21.1 & 24.6 & S (20) & IT9 (36) \\
Aluminum & -5.33 & 32.9 & 38.2 & S (20) & IT10 (58) \\
Magnesium & & -8.32 & 51.4 & 59.8 & T (60) & IT11 (90) \\
\hline & 0.50 & -5.33 & 32.9 & 38.2 & S (20) & IT10 (58) \\
Aluminum & 0.45 & -7.20 & 36.2 & 43.4 & T (60) & IT10 (58) \\
& 0.40 & -9.86 & 40.8 & 50.6 & T (60) & IT10 (58) \\
& 0.35 & -13.9 & 47.3 & 61.1 & T (60) & IT11 (90) \\
& 0.30 & -20.3 & 57.2 & 77.5 & T (60) & IT11 (90) \\
\hline
\end{tabular}

SLD: Symmetry line direction

FD: Gripping force direction

* Form tolerance $t=\Delta d / 2$ 
could damage parts fitted [20, 21]. So, shrink fitted parts should be manufactured precisely.

Figure 8 shows the correlation between partially pressurized and fully pressurized parts. The maximum dimension of the partially pressurized part is smaller than the fully pressurized one. A correction factor would be useful to estimate the maximum size of the bore. In this situation, the correction factor equals to 0.2 for the same dimensions and different materials. In the figure, it can be clearly seen that wall-thickness is another important parameter to estimate the maximum bore dimension as stated earlier.

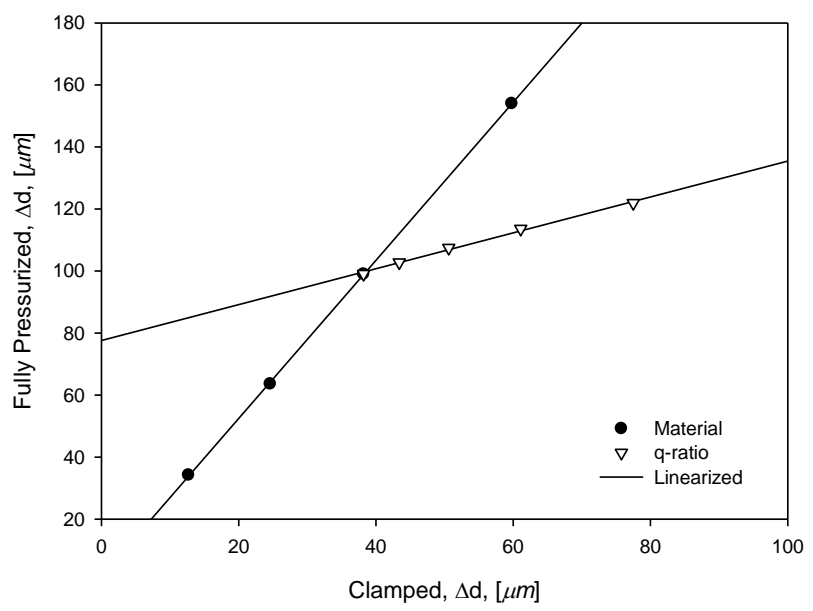

Figure 8. Correlaiton between dimensional variations for partially pressurized and fully pressurized parts.

For thin-walled workpieces, using thin-walled pressurized vessel formula is a more convenient way to calculate deformation rather than using the thickness factor described here. When implementing the correction factor, $k_{c r}$, and the thickness factor, $k_{t}$, in Eq. (8), it yields:

$$
\Delta d=\frac{k_{t f} k_{c f} d}{E}\left(\sigma_{r}-v \sigma_{\theta}\right)
$$

Eq. (9) allows estimating the maximum dimension of the bore and the tolerance class in which it belongs. The proposed factor should be verified experimentally and could be expanded for further use. This study does not consider residual and thermal stresses caused by the manufacturing process that could also affect the out-of-roundness of the workpiece [22, 23]. The thermal expansion could be neglected under proper cooling conditions. It should be kept in mind that diameter measurement might be erroneous due to the triangulation of part via a linear inside micrometer. The minimum and maximum sizes given in this paper were accepted as twice the radius assuming that measurements would be gathered using a selfcentering inside micrometer.

\section{Conclusions}

In this paper, two important parameters were studied numerically in order to reduce the rejection rate of the manufacturing process. All results considered, the main conclusion could be drawn as follows:

- The bore profile of the workpiece could be estimated by using the modified formula suggested in this paper.

- Young's modulus affects significantly deformation level of clamped parts. The lower Young's modulus, the more the deformation of the bore. Materials with a low Young's modulus could be out of tolerance limit when clamped by three-jaw chuck. For precise machining, other types of clamping should be considered.

- Another parameter investigated here is the ratio of wall thickness to bore diameter $\left(s / d_{i}\right)$. Thin-walled workpieces are more prone to deformity. Avoiding from overstraining of parts could be useful to improve the quality grade.

- Generally, to reduce the rejection rate and improve the quality grade of dimension with the same equipment, the clamping force should be carefully applied.

- Even if circular form tolerance is acceptable, dimensional tolerance could be still raw. It is not seen possible to achieve high-quality grade (low number) using a three-jaw chuck. The correction factors recommended in this paper should help engineers to estimate bore dimension tolerances.

- From a viewpoint of mass production, a noncontrollable clamping force could be responsible for the variation of dimensions among workpiece manufactured under the same circumstances.

- The present study applies clamping force throughout the length of the workpiece. For long parts, clamping force only affects the dimensions of the chuck side. Tolerances of part at free end would vary depending on other manufacturing conditions such as runout.

\section{Nomenclature}




$\begin{array}{ll}a & : \text { Cutting depth } \\ A & : \text { The area of contact } \\ d_{g} & : \text { Gripping diameter } \\ d_{i} & : \text { The inner diameter of cylindrical part } \\ d_{m} & : \text { Machining diameter } \\ d_{o} & : \text { The outer diameter of cylindrical part } \\ D_{b} & : \text { The initial bore diameter of workpiece } \\ D_{f} & : \text { The final bore diameter of workpiece } \\ E & : \text { Young's modulus } \\ f & : \text { Feed rate } \\ F & : \text { Force } \\ F_{c} & : \text { Cutting force } \\ F_{g} & : \text { Gripping force } \\ k_{c} & : \text { Specific cutting force } \\ k_{c f} & : \text { Correction factor } \\ k_{t f} & : \text { Thickness factor } \\ s & : \text { The wall thickness of cylindrical parts } \\ S & : \text { The material machined } \\ S_{k} & : \text { Safety factor } \\ p & : \text { Pressure } \\ q & : \text { The ratio outer diameter to inner diameter } \\ r & : \text { indicates the radial axis } \\ \Delta d & : \text { Dimensional variation } \\ \Delta s & : \text { Additional chip thickness } \\ \mu_{g} & : \text { The friction coefficient between workpiece } \\ \text { and jaws } \\ \theta & : \text { indicates the tangential axis } \\ \sigma_{\theta} & : \text { Tangential stress } \\ & \end{array}$

\section{References}

[1] Li B., Melkote S.N., Fixture clamping force optimisation and its impact on workpiece location accuracy. Int J Adv Manuf Technol. 17 (2001) 104-113.

[2] Güven F., Contact Pressure Losses in Shrink Fitted Assembly Due to Triangular Hub Form. In: 5th International Conference on Advances in Mechanical Engineering. İstanbul (2019) 950-955.

[3] Feng P.F., Yu D.W., Wu Z.J. and Uhlmann E., Jaw-chuck stiffness and its influence on dynamic clamping force during high-speed turning. Int. J Mach. Tools Manuf. 48 (2008) 1268-1275.

[4] Rahman M., Factors affecting the machining accuracy of a chucked workpiece. Precis. Eng. 8 (1986) 34-40.

[5] Brinksmeier E., Sölter J. and Grate C., Distortion engineering - identification of causes for dimensional and form deviations of bearing rings. CIRP Ann. - Manuf. Technol. 56 (2007) 109-112.
[6] Kessler O., Prinz C., Sackmann T., Nowag L., Surm H., Frerichs F., Lübben Th. and Zoch W., Experimental Study of Distortion Phenomena in Manufacturing Chains. Mat.-wiss. u. Werkstofftech., 37 (2006) 11-18. DOI: 10.1002/mawe.200500975.

[7] Malluck J.A., Melkote S.N., Modeling of Deformation of Ring Shaped Workpieces Due to Chucking and Cutting Forces. J. Manuf. Sci. Eng. Feb 126(1) (2004) 141-147

[8] Estrems M., Arizmendi M., Cumbicus W.E. and López A., Measurement of Clamping Forces in a 3 Jaw Chuck through an Instrumented Aluminium Ring. Procedia Eng. 132 (2015) 456-463.

[9] Estrems M., Arizmendi M., Zabaleta A.J., and Gil A., Numerical Method to Calculate the Deformation of Thin Rings during Turning Operation and its Influence on the Roundness Tolerance. Procedia Eng. 132 (2015) 872-879.

[10] Estrems M., Carrero-Blanco J., Cumbicus W.E., de Francisco O. and Sánchez H.T., Contact mechanics applied to the machining of thin rings. Procedia Manuf. 13 (2017) 655-662.

[11] Bajpai S., Optimization of workpiece size for turning accurate cylindrical parts. Int J Mach. Tool Des. Res. 12 (1972) 221-228.

[12] Maračeková M., Zvončan M. and Görög A. Effect of clamping pressure on parts inaccuracy in turning. Teh. Vjesn. 19(3) (2012) 509-512.

[13] Görög A., Görögová I., Research of the Influence of Clamping Forces on the Roundness Deviations of the Pipes Turned Surface. Res. Pap. Fac. Mater. Sci. Technol. Slovak Univ Technol 26(42) (2018) 47-54.

[14] Shawky A., Rosenberger T. and Elbestawi M., In-process monitoring and control of thickness error in machining hollow shafts. Mechatronics 8 (1998) 301-322.

[15] Beekhuis B., Stoebener D. and Brinksmeier E., Adapted Non-Circular Soft Turning of Bearing rings - Impact of process machine interactions on compensation potential. Procedia CIRP 1 (2012) 540-545.

[16] Stöbener D., Beekhuis B., Application of an in situ measuring system for the compensation of wall thickness variations during turning of thinwalled rings. CIRP Annals 62(1) (2013) 511514.

[17] Jones F.D., Oberg E. and Horton H.L. and Henry H.R., Machinery's handbook 27th Eds. Industrial Press, (2004).

[18] Schmid S.R., Hamrock B.J. and Jacobson B.O., Fundamentals of machine elements. 3rd ed. Boca Raton: CRC Press, 2013. 
[19] Norm ISO 286-1:2010. Geometrical product specifications (GPS) - ISO code system for tolerances on linear sizes - Part 1: Basis of tolerances, deviations and fits. 2010.

[20] Güven F., Rende H., Influence of Contact Pressure on Surface Roughness Losses in Shrink Fitted Joints. In: 8th International Advanced Technologies Symposium. (2017) 3115-3119.

[21] Rende H., Güven F., Sıkı geçme bağlantılarında malzemeye bağlı yüzey pürüzlülügü kayıp katsayısının belirlenmesi. Mühendis ve Makina 665 (2015) 46-52.

[22] Volkmuth J., Lane S., Jung M. and Sjöblom U.,. Uneven residual stresses in bearing rings prior to hardening and their effect on shape changes after hardening. HTM - Haerterei-Technische Mitteilungen. 60 (2005) 317-322.

[23] Neslušan M., Mrkvica I., Čep R., Kozak D., and Konderla R., Deformations after heat treatment and their influence on cutting process. Teh Vjesn 18 (2011) 601-608. 